\title{
Farelo de castanha de caju em rações para frangos de corte
}

\author{
Ednardo Rodrigues Freitas ${ }^{(1)}$, Maria de Fátima Freire Fuentes ${ }^{(1)}$, Amadeu dos Santos Júnior ${ }^{(1)}$, \\ Maria Elizimar Felizardo Guerreiro ${ }^{(1)}$ e Gastão Barreto Espíndola ${ }^{(1)}$
}

(1)Universidade Federal do Ceará, Dep. de Zootecnia, Caixa Postal 12.168, Campus do Pici, CEP 60355-970 Fortaleza, CE. E-mail:
ednardo@ufc.br, fatimaf@ufc.br, elizimar@ufc.br, gbespin@uol.com.br

Resumo - O objetivo deste trabalho foi avaliar o desempenho de frangos de corte alimentados com ração com farelo de castanha de caju (FCC). O delineamento experimental foi inteiramente casualizado, com seis tratamentos e oito repetições de 15 aves cada. Os tratamentos consistiram em seis rações isonutrientes com inclusão de 0, 5, 10, 15, 20 e 25\% de ração com farelo de castanha de caju. O consumo de ração não foi influenciado pelos tratamentos. Entretanto, o aumento do FCC na ração promoveu aumento linear no ganho de peso, em todas as fases, e melhora linear na conversão alimentar, na fase inicial e no período total. Em relação ao controle, observou-se que, na fase inicial, as aves alimentadas com a ração com 25\% de FCC apresentaram maior ganho de peso e melhor conversão alimentar. Na fase final e no período total de criação, a conversão melhorou a partir de $10 \%$ de inclusão, enquanto o ganho de peso foi maior a partir de $15 \%$ de inclusão. O rendimento de carcaça e a gordura abdominal não foram influenciados; os índices econômicos melhoraram com a inclusão do FCC. O FCC pode ser incluído nas rações de frangos de corte em proporções de até 25\%.

Termos para indexação: consumo de ração, conversão alimentar, ganho de peso.

\section{Cashew nut meal in broiler diets}

\begin{abstract}
The objective of this work was to evaluate the performance of broilers fed diets containing cashew nut meal (CNM). The experiment followed a completely randomized design with six treatments and eight replicates of 15 broilers each. Treatments consisted of six isonutrient diets containing 0, 5, 10, 15, 20 and 25\% of CNM. Feed intake was not affected by CNM levels. However, increasing CNM in diets promoted a linear increase in weight gain, in all phases, and a linear improvement in broiler feed conversion for the initial and total period. Compared to control diet, broilers fed diets with 25\% of CNM inclusion, in the initial phase, showed the highest weight gain and the best feed conversion. During the final phase and all the feeding period, feed conversion was improved in broilers fed up to 10\% CNM inclusion; and weight gain increased when inclusion of CNM was 15\% or higher. Carcass yield and abdominal fat were not affected. Inclusion of CNM in diet improved economic efficiency of broiler production. CNM can be included up to $25 \%$ in broiler diets.
\end{abstract}

Index terms: feed conversion, feed intake, weight gain.

\section{Introdução}

Na atividade avícola, a alimentação é o ponto crítico, pois representa cerca de 60 a $70 \%$ dos custos de produção da carne de frango; além disso, no Brasil, os principais ingredientes utilizados nas dietas de aves, o milho e a soja, são produtos também consumidos pelo homem. No Ceará, a produção de milho é insuficiente para atender a demanda, enquanto a soja é totalmente adquirida fora do Estado, o que faz com que haja aumento dos custos da ração.
Nesse contexto, a busca por alimentos alternativos é de fundamental importância para a indústria avícola. No Nordeste e, principalmente, no Ceará, entre os alimentos alternativos destaca-se o farelo de castanha de caju (FCC), subproduto oriundo do beneficiamento da castanha de caju (Anacardium occidentale L.).

O Brasil é o segundo produtor mundial de castanha de caju, e o Estado do Ceará é o principal produtor brasileiro, com produção de 108.051 t de amêndoas em 2003 (Produção..., 2003). Estima-se que entre 2 e 5\% da castanha de caju processada sejam impróprios para o consu- 
mo humano, e se constituem refugo, que pode ser utilizado na alimentação animal (Pimentel, 1992). De acordo com esse autor, o FCC é constituído por: pedaços de amêndoas com pintas pretas, causadas por pragas e doenças; pedaços com manchas e com películas em conseqüência do processamento; amêndoas inteiras e pedaços mofados pelas condições de armazenamento.

O FCC apresenta composição que lhe confere alto valor energético (6.306 a 6.764 kcal de energia bruta por quilograma de matéria natural) e protéico (22,15 a 38,12\% de proteína bruta) (Embrapa, 1991; Onifade et al., 1998, 1999; Ojewola et al., 2004). Em razão destas características, pode ser um substituto parcial do milho e do farelo de soja nas rações de aves. Segundo Onifade et al. (1999), o FCC pode ser comparado à soja integral, como fonte moderada de proteína, e excelente fonte de energia, por apresentar elevado teor de gordura. Além disso, o baixo incremento calórico, associado ao metabolismo da gordura, pode ser vantagem para a inclusão desse alimento nas rações de aves criadas em ambientes com alta temperatura. Ao utilizar o FCC na alimentação de frangas na fase de recria, Onifade et al. (1998) observaram que sua inclusão proporcionou ganhos de peso similares, menor consumo de ração e melhor conversão alimentar. Segundo os autores, esses resultados se devem ao melhor metabolismo da gordura oriunda do FCC e à regulação da ingestão de energia, dada a alta densidade energética desse alimento. Quando avaliaram o efeito da substituição da proteína do farelo de soja pela do FCC, em rações de frangos de corte, Ojewola et al. (2004) verificaram que o consumo de ração e o ganho de peso não foram influenciados pela inclusão do FCC, ao passo que a conversão alimentar melhorou.

O presente trabalho teve como objetivo avaliar o desempenho de frangos de corte alimentados com rações com farelo de castanha de caju.

\section{Material e Métodos}

O experimento foi realizado em um galpão convencional dividido em boxes (1x1,5 m). Foram utilizados 720 pintos machos de uma marca comercial. As aves foram distribuídas em um delineamento inteiramente casualizado, com seis tratamentos e oito repetições, com 15 aves por unidade experimental.

Os tratamentos foram constituídos de uma ração testemunha, sem FCC, e de rações com a inclusão de FCC nas porcentagens de $5,10,15,20$ e $25 \%$. As rações experimentais (Tabelas 1 e 2) foram formuladas com

Tabela 1. Composição porcentual e calculada de rações, para frango de corte de 1 a 21 dias de idade, com farelo de castanha de caju (FCC).

\begin{tabular}{|c|c|c|c|c|c|c|}
\hline \multirow[t]{2}{*}{ Ingrediente } & \multicolumn{6}{|c|}{ Níveis de FCC (\%) } \\
\hline & 0 & 5 & 10 & 15 & 20 & 25 \\
\hline Milho & 60,170 & 58,794 & 53,213 & 47,174 & 41,138 & 35,100 \\
\hline Farelo de soja & 34,388 & 32,324 & 31,043 & 29,847 & 28,651 & 27,456 \\
\hline $\mathrm{FCC}$ & 0,000 & 5,000 & 10,000 & 15,000 & 20,000 & 25,000 \\
\hline Óleo de soja & 1,739 & 0,155 & 0,000 & 0,000 & 0,000 & 0,000 \\
\hline Calcário & 1,069 & 1,088 & 1,096 & 1,104 & 1,111 & 1,118 \\
\hline Fosfato bicálcico & 1,708 & 1,695 & 1,691 & 1,688 & 1,684 & 1,681 \\
\hline Suplemento vitamínico ${ }^{(1)}$ & 0,300 & 0,300 & 0,300 & 0,300 & 0,300 & 0,300 \\
\hline Suplemento mineral ${ }^{(2)}$ & 0,100 & 0,100 & 0,100 & 0,100 & 0,100 & 0,100 \\
\hline DL - Metionina 99\% & 0,134 & 0,146 & 0,162 & 0,179 & 0,196 & 0,213 \\
\hline $\mathrm{L}-\mathrm{Lisina} \mathrm{HCl}$ & 0,000 & 0,000 & 0,000 & 0,004 & 0,010 & 0,107 \\
\hline Antioxidante - BHT & 0,050 & 0,050 & 0,050 & 0,050 & 0,050 & 0,050 \\
\hline Sal comum & 0,342 & 0,348 & 0,354 & 0,360 & 0,366 & 0,372 \\
\hline Inerte & 0,000 & 0,000 & 1,991 & 4,198 & 6,404 & 8,610 \\
\hline Total & 100,000 & 100,000 & 100,000 & 100,000 & 100,000 & 100,000 \\
\hline \multicolumn{7}{|l|}{ Composição calculada } \\
\hline EM (kcal kg-1) & 3.000 & 3.000 & 3.000 & 3.000 & 3.000 & 3.000 \\
\hline Proteína bruta (\%) & 22,000 & 22,000 & 22,000 & 22,000 & 22,000 & 22,000 \\
\hline Extrato etéreo (\%) & 3,984 & 4,137 & 5,588 & 7,179 & 8,770 & 10,361 \\
\hline Fibra bruta $(\%)$ & 3,306 & 3,460 & 3,589 & 3,716 & 3,843 & 3,969 \\
\hline Cálcio (\%) & 0,940 & 0,940 & 0,940 & 0,940 & 0,940 & 0,940 \\
\hline Fósforo disponível (\%) & 0,420 & 0,420 & 0,420 & 0,420 & 0,420 & 0,420 \\
\hline Sódio $(\%)$ & 0,180 & 0,180 & 0,180 & 0,180 & 0,180 & 0,180 \\
\hline Lisina $(\%)$ & 1,183 & 1,183 & 1,183 & 1,183 & 1,183 & 1,183 \\
\hline Metionina (\%) & 0,475 & 0,475 & 0,475 & 0,475 & 0,475 & 0,475 \\
\hline Metionina + cistina $(\%)$ & 0,840 & 0,840 & 0,840 & 0,840 & 0,840 & 0,840 \\
\hline
\end{tabular}


milho, farelo de soja, FCC e óleo, tendo-se incluído areia lavada como material inerte. No cálculo das rações, foram considerados os valores de composição e energia metabolizável dos alimentos, propostos pela Embrapa (1991), e as exigências nutricionais, recomendadas pelo National Research Council (1994), para a fase inicial (1 a 21 dias de idade) e fase final (21 a 42 dias de idade). Para ambas as fases de criação, as rações experimentais foram calculadas para serem isonutrientes.

Os pintos foram adquiridos em um incubatório comercial e vieram vacinados contra as doenças de Marek e Gumboro e, aos sete dias de idade, foram vacinados, via água, contra a doença de New Castle. No alojamento, os pintos foram pesados e distribuídos aleatoriamente nos boxes. O aquecimento foi feito por lâmpadas incandescentes de $100 \mathrm{~W}$.

As aves receberam, durante todo o experimento, ração e água à vontade e, a partir da segunda semana, foram submetidas a um programa com 23 horas de luz contínua e uma hora de escuro, com a iluminação noturna feita por lâmpadas fluorescentes.
Foram avaliados: o consumo de ração (grama por ave); o ganho de peso (grama por ave); e a conversão alimentar na fase inicial, fase final e no período total (1 a 42 dias). Para isso, as aves e as rações foram pesadas no início e no final de cada fase.

Aos 42 dias de idade, procedeu-se à avaliação das características de carcaça: rendimento de carcaça e porcentagem de gordura abdominal. Foi selecionada uma ave de cada parcela, com peso próximo ao peso médio obtido para a parcela e, após jejum de 12 horas, as aves foram abatidas por deslocamento cervical. $\mathrm{O}$ rendimento de carcaça foi determinado pela relação entre o peso da carcaça quente (eviscerada e sem pés, cabeça, pescoço e vísceras comestíveis) e o peso vivo, enquanto, a proporção da gordura abdominal foi calculada em relação ao peso da carcaça resfriada.

Para verificar a viabilidade econômica da inclusão do FCC nas rações, determinou-se o custo da ração (CR) por quilograma de ganho de peso vivo, e calculou-se o índice de eficiência econômica (IEE) e o índice de cus-

Tabela 2. Composição porcentual e calculada de rações, para frango de corte de 21 a 42 dias de idade, com farelo de castanha de caju (FCC).

\begin{tabular}{|c|c|c|c|c|c|c|}
\hline \multirow[t]{2}{*}{ Ingrediente } & \multicolumn{6}{|c|}{ Níveis de FCC (\%) } \\
\hline & 0 & 5 & 10 & 15 & 20 & 25 \\
\hline Milho & 62,370 & 60,994 & 59,619 & 57,108 & 51,072 & 45,036 \\
\hline Farelo de soja & 29,889 & 27,825 & 25,761 & 23,900 & 22,691 & 21,482 \\
\hline $\mathrm{FCC}$ & 0,000 & 5,000 & 10,000 & 15,000 & 20,000 & 25,000 \\
\hline Óleo de soja & 4,367 & 2,782 & 1,198 & 0,000 & 0,000 & 0,000 \\
\hline Calcário & 1,215 & 1,234 & 1,253 & 1,269 & 1,276 & 1,284 \\
\hline Fosfato bicálcico & 1,365 & 1,353 & 1,340 & 1,330 & 1,327 & 1,323 \\
\hline Suplemento vitamínico ${ }^{(1)}$ & 0,300 & 0,300 & 0,300 & 0,300 & 0,300 & 0,300 \\
\hline Suplemento mineral $^{(2)}$ & 0,100 & 0,100 & 0,100 & 0,100 & 0,100 & 0,100 \\
\hline DL - Metionina $99 \%$ & 0,068 & 0,080 & 0,092 & 0,105 & 0,122 & 0,139 \\
\hline $\mathrm{L}-\mathrm{Lisina} \mathrm{HCl}$ & 0,000 & 0,000 & 0,000 & 0,004 & 0,010 & 0,107 \\
\hline Antioxidante - BHT & 0,050 & 0,050 & 0,050 & 0,050 & 0,050 & 0,050 \\
\hline Sal comum & 0,276 & 0,282 & 0,287 & 0,293 & 0,299 & 0,304 \\
\hline Inerte & 0,000 & 0,000 & 0,000 & 0,541 & 2,753 & 4,965 \\
\hline Total & 100,000 & 100,000 & 100,000 & 100,000 & 100,000 & 100,000 \\
\hline \multicolumn{7}{|l|}{ Composição calculada } \\
\hline $\mathrm{EM}\left(\mathrm{kcal} \mathrm{kg}^{-1}\right)$ & 3.200 & 3.200 & 3.200 & 3.200 & 3.200 & 3.200 \\
\hline Proteína bruta (\%) & 20,000 & 20,000 & 20,000 & 20,000 & 20,000 & 20,000 \\
\hline Extrato etéreo (\%) & 6,649 & 6,801 & 6,954 & 7,457 & 9,048 & 10,639 \\
\hline Fibra bruta (\%) & 3,053 & 3,206 & 3,360 & 3,506 & 3,632 & 3,758 \\
\hline Cálcio (\%) & 0,900 & 0,900 & 0,900 & 0,900 & 0,900 & 0,900 \\
\hline Fósforo disponível (\%) & 0,350 & 0,350 & 0,350 & 0,350 & 0,350 & 0,350 \\
\hline Sódio (\%) & 0,150 & 0,150 & 0,150 & 0,150 & 0,150 & 0,150 \\
\hline Lisina $(\%)$ & 1,052 & 1,052 & 1,052 & 1,052 & 1,052 & 1,052 \\
\hline Metionina (\%) & 0,383 & 0,383 & 0,383 & 0,383 & 0,383 & 0,383 \\
\hline Metionina + cistina $(\%)$ & 0,720 & 0,720 & 0,720 & 0,720 & 0,720 & 0,720 \\
\hline
\end{tabular}

(1)Suplemento vitamínico (fornecido por quilograma de ração): vitamina A, 6.510 UI; vitamina B1, 1,50 mg; vitamina B12, $12 \mu \mathrm{g}$; vitamina B2, 4,05 mg; vitamina B6, 2,01 mg; vitamina $\mathrm{D}_{3}, 2.220 \mathrm{UI}$; vitamina $\mathrm{E}, 12 \mathrm{mg}$; vitamina $\mathrm{K}_{3}, 2,01 \mathrm{mg}$; ácido fólico, 0,81 mg; pantotenato de cálcio, $12 \mathrm{mg}$; colina, 0,51 g; niacina, $36 \mathrm{mg}$; antioxidante, 10,2 g; promotor de crescimento, 0,36 g; coccidiostático, 1,02 g; Se, 0,15 mg. (2)Suplemento mineral (fornecido por quilograma de ração): Cu, 10 mg; Zn, 50 mg; Fe, 40 mg; Mn, 65 mg; I, 1 mg. 
to (IC), conforme Furlan et al. (2001). No cálculo do custo da ração, foram considerados os valores de $\mathrm{R} \$ 0,37, \mathrm{R} \$ 0,62$, R\$ 0,33 e R\$ 1,90 para o quilograma de milho, farelo de soja, FCC e óleo de soja, respectivamente.

A análise estatística dos dados foi realizada, utilizando-se o Statistical Analyses System (SAS Institute, 1996). Os graus de liberdade, referentes aos níveis de inclusão do FCC, excluindo-se a ração testemunha (nível zero de inclusão), foram desdobrados em polinômios, para estabelecer a curva que melhor descrevesse o comportamento dos dados. Para a comparação dos resultados, obtidos com cada uma das proporções de inclusão do FCC, em relação à ração testemunha, foi utilizado o teste de Dunnett a 5\% de probabilidade.

\section{Resultados e Discussão}

Os dados de desempenho, nas diferentes fases de criação, e as características de carcaça dos frangos de corte, alimentados com as diferentes proporções de FCC na ração, são apresentados na Tabela 3.

$\mathrm{Na}$ fase inicial (1 a 21 dias de idade) os tratamentos não influenciaram o consumo de ração, enquanto o ganho de peso e a conversão alimentar foram influenciados pela inclusão do FCC nas rações. Embora tenham sido observadas melhoras no ganho de peso e na conversão, com a inclusão do FCC nas rações, apenas quando as aves receberam a ração com $25 \%$ de inclusão, os resultados para estas duas variáveis foram melhores em relação aos do grupo controle.

Na análise de regressão, excluindo-se o controle, houve o efeito linear significativo tanto para o ganho de

Tabela 3. Desempenho e características de carcaça de frangos de corte, alimentados com rações com diferentes porcentagens de inclusão do farelo de castanha de caju (FCC).

\begin{tabular}{|c|c|c|c|c|c|c|c|}
\hline \multirow{2}{*}{ Variáveis } & \multicolumn{6}{|c|}{ Porcentagem de inclusão do FCC } & \multirow{2}{*}{$\begin{array}{l}\mathrm{CV} \\
(\%)\end{array}$} \\
\hline & 0 & 5 & 10 & 15 & 20 & 25 & \\
\hline & \multicolumn{6}{|c|}{ Fase inicial (1 a 21 dias de idade) } & \\
\hline Consumo de ração (g por ave) ${ }^{(1)}$ & 979 & 1.009 & 958 & 995 & 1.006 & 1.004 & 4,09 \\
\hline Ganho de peso (g por ave) $)^{(2)}$ & 649 & 645 & 640 & 661 & 685 & $703 *$ & 4,69 \\
\hline \multirow[t]{2}{*}{ Conversão alimenta $^{(2)}$} & 1,51 & 1,57 & 1,50 & 1,51 & 1,47 & $1,43^{*}$ & 3,60 \\
\hline & \multicolumn{6}{|c|}{ Fase final (21 a 42 dias de idade) } & \\
\hline Consumo de ração (g por ave) ${ }^{(1)}$ & 2.596 & 2.536 & 2.507 & 2.681 & 2.582 & 2.627 & 5,55 \\
\hline Ganho de peso (g por ave) ${ }^{(2)}$ & 1.188 & 1.218 & 1.273 & $1.329 *$ & $1.320^{*}$ & $1.312 *$ & 6,69 \\
\hline \multirow[t]{2}{*}{ Conversão alimentar $^{(1)}$} & 2,19 & 2,08 & $1,97 *$ & $2,02 *$ & $=1,95^{*}$ & $2,00 *$ & 4,77 \\
\hline & \multicolumn{7}{|c|}{ Período total (1 a 42 dias de idade) } \\
\hline Consumo de ração (g por ave) ${ }^{(1)}$ & 3.575 & 3.550 & 3.464 & 3.676 & 3.587 & 3.601 & 4,53 \\
\hline Ganho de peso (g por ave) $)^{(2)}$ & 1.837 & 1.857 & 1.912 & $1.990 *$ & $2.005^{*}$ & $2.001 *$ & 5,04 \\
\hline Conversão alimentar ${ }^{(2)}$ & 1,95 & 1,92 & $1,81^{*}$ & $1,85^{*}$ & $1,79 *$ & $1,80 *$ & 3,15 \\
\hline Rendimento de carcaça $(\%)^{(1)}$ & 69,26 & 69,86 & 70,05 & 69,37 & 69,80 & 70,51 & 2,58 \\
\hline Gordura abdominal $(\%)^{(1)}$ & 2,53 & 2,52 & 2,85 & 2,64 & 2,86 & 2,76 & 15,60 \\
\hline
\end{tabular}

peso quanto para a conversão alimentar. De acordo com as equações obtidas com a inclusão de FCC na ração, nas proporções acima de $5 \%$ o ganho de peso e a conversão alimentar melhoraram, sendo que para cada $1 \%$ de inclusão, acima desta proporção, o aumento no ganho de peso foi de 3,26 g por ave, enquanto a conversão melhorou em 0,006 pontos (Tabela 4).

$\mathrm{Na}$ fase final (21 a 42 dias de idade), e no período total de criação (1 a 42 dias de idade), observou-se que o consumo de ração não foi alterado pela inclusão do FCC nas rações, enquanto o ganho de peso e a conversão diferiram entre os tratamentos. Observou-se que, em ambas as fases, a inclusão de FCC a partir de 10\% melhorou a conversão alimentar, e o ganho de peso foi significativamente maior a partir de 15\% de inclusão.

$\mathrm{Na}$ análise de regressão, foi observado efeito linear no ganho de peso (Tabela 4). Nas inclusões acima de $5 \%$, a cada $1 \%$ de inclusão do FCC nas rações, houve melhora do ganho de peso em 4,85 g por ave, na fase final, e 7,61 g por ave no período total de criação.

Quanto à conversão alimentar, a análise de regressão não foi significativa para a fase final, enquanto no período total de criação observou-se efeito linear, melhora esta estimada em 0,005 pontos para cada $1 \%$ de inclusão do FCC, em níveis acima de 5\%.

O consumo voluntário de ração pelas aves, dentro de certos limites, é regulado pela ingestão de energia, e está, assim, relacionado ao nível energético da ração, de forma que rações com níveis de energia elevados podem promover redução em seu consumo (Leeson \& Summers, 2001). Considerando-se que as rações foram formuladas para serem isonutrientes, esperava-se que a ingestão de alimento pelos frangos de corte não variasse entre os tratamentos.

Os resultados obtidos neste trabalho diferem, em parte, dos obtidos por Onifade et al. (1998), que utilizaram o FCC na alimentação de frangas na fase de recria e observaram que a inclusão dessa ração proporcionou

Tabela 4. Equações de regressão e coeficientes de determinação, obtidos nas análises de regressão, do farelo de castanha de caju (FCC), excluindo-se o controle.

\begin{tabular}{lcc}
\hline Variáveis & Equações de regressão & $\mathrm{R}^{2}$ \\
\hline & Fase inicial (1 a 21 dias de idade) & \\
Ganho de peso (g por ave) & $\mathrm{Y}=617+3,26 \mathrm{X}$ & 0,35 \\
Conversão alimentar & $\mathrm{Y}=1,58-0,006 \mathrm{X}$ & 0,39 \\
\hline \multicolumn{3}{c}{ Fase final (21 a 42 dias de idade) } \\
Ganho de peso (g por ave) & $\mathrm{Y}=1219+4,85 \mathrm{X}$ & 0,15 \\
\hline & Período total (1 a 42 dias de idade) & \\
Ganho de peso (g por ave) & $\mathrm{Y}=1839+7,61 \mathrm{X}$ & 0,25 \\
Conversão alimentar & $\mathrm{Y}=1,90-0,005 \mathrm{X}$ & 0,28 \\
\hline
\end{tabular}


ganhos de peso similares, menor consumo e melhor conversão alimentar. De acordo com esses autores, tais resultados ocorreram em razão do melhor metabolismo da gordura, oriunda do FCC, e da regulação da ingestão de energia, dada a alta densidade energética desse alimento, uma vez que as rações não foram formuladas para serem isoenergéticas. Resultados comparáveis aos deste trabalho foram obtidos por Ojewola et al. (2004), que avaliaram os efeitos da substituição da proteína do farelo de soja, das rações de frangos de corte, pelo FCC, e constaram que o consumo de ração e o ganho de peso dos frangos não variaram entre os tratamentos, porém a conversão alimentar melhorou com o aumento do FCC nas rações. Segundo os autores, essa melhora ocorreu em razão do incremento da quantidade de gordura nas rações com a inclusão do FCC.

O aumento no ganho de peso e a melhora na conversão alimentar, causada pela inclusão de alimentos ricos em gordura, ou a suplementação de gordura na ração de frangos de corte, têm sido atribuídos ao aumento da densidade energética, ao efeito extra-calórico e ao efeito extra-metabólico das gorduras. O efeito extra-calórico das gorduras consiste no aumento da disponibilidade dos nutrientes de outros ingredientes da ração. O efeito extra-metabólico resulta em melhoria da eficiência energética, em função do aumento da energia líquida da ração, decorrente do menor incremento calórico das gorduras, em razão do seu metabolismo (Sakomura et al., 1998, 2004).

Para as características de carcaça, observou-se que a inclusão do FCC na ração não influenciou significativamente o rendimento de carcaça e a quantidade de gordura abdominal (Tabela 3).

Há relatos dos efeitos da nutrição sobre o rendimento de carcaça e a quantidade de gordura abdominal dos frangos de corte (Waldroup, 1991; Leeson \& Summers, 2001). Entretanto, as alterações nestas características, principalmente na gordura abdominal, parecem estar mais sujeitas aos efeitos do nível de energia da ração (Oliveira Neto et al., 2000) e das relações energia:proteína ou energia:aminoácidos nas rações, do que à inclusão de um alimento em rações isonutrientes (Sakomura et al., 1998; Grangeiro et al., 2001).

Jensen (1991) comenta que quando são incorporados nas rações ingredientes com valores de energia metabolizável subestimados, pode ocorrer aumento da relação energia:proteína da ração, o que gera maiores valores de gordura abdominal. Como as rações utilizadas neste trabalho foram calculadas para serem isonutrientes, e não houve diferença significativa no consumo de ração, a ausência de variação sobre as características de carcaça pode ser considerada como resultado esperado.

Embora não tenha sido feita a análise da composição em ácidos graxos da gordura dos frangos, observou-se que a gordura das aves alimentadas com as rações com maior inclusão de FCC apresentava-se menos consistente, quando comparada à gordura das aves alimentadas com a ração sem inclusão desse alimento (controle). Esse fato pode ser atribuído ao aumento da quantidade dos ácidos graxos insaturados na ração, com a inclusão do FCC, uma vez que a composição lipídica da ração fornecida às aves influencia na composição da gordura dos frangos (Martins et al., 2003; Baião \& Lara, 2005).

Os resultados da análise econômica estão descritos na Tabela 5. Excluindo-se o controle, verificou-se que com a inclusão do FCC nas rações houve redução linear no custo da ração por quilograma de ganho de peso vivo, e melhora linear nos índices de eficiência econômica e custo. Pelo teste de Dunnett, todos os níveis de inclusão do FCC diferiram da ração testemunha, que apresentou o maior custo por quilograma produzido e, conseqüentemente, os piores índices de eficiência econômica e custo. Esses resultados indicam a viabilidade econômica da utilização do FCC nas rações de frangos de corte.

Ojewola et al. (2004) verificaram que a substituição da proteína do farelo de soja pela do FCC, na ração de frangos de corte, resultou em menor custo do quilograma de ração e do custo com alimentação por ave.

Os resultados obtidos neste trabalho demonstraram que a inclusão do FCC, até $25 \%$, nas rações de frangos de corte, é economicamente viável para as diferentes fases de criação, sem comprometer o desempenho e as características de carcaça.

Tabela 5. Custo da ração (CR) por quilograma de ganho de peso vivo, índice de eficiência econômica (IEE) e índice de custo (IC).

\begin{tabular}{|c|c|c|c|c|c|c|c|}
\hline \multirow[t]{2}{*}{ Variável } & \multicolumn{6}{|c|}{ Porcentagem de inclusão do FCC (\%) } & \multirow{2}{*}{$\begin{array}{l}\text { CV } \\
(\%)\end{array}$} \\
\hline & 0 & 5 & 10 & 15 & 20 & 25 & \\
\hline$\overline{\mathrm{CR}}(\mathrm{R} \$ / \mathrm{kg} \text { de ganho) })^{(1)}$ & 0,58 & 0,54 & 0,49 & 0,48 & 0,45 & 0,44 & 3,42 \\
\hline $\operatorname{IEE}(\%)^{(2)}$ & 76 & $81^{*}$ & $90 *$ & $92 *$ & $98 *$ & 100 & 3,04 \\
\hline $\mathrm{IC}(\%)^{(3)}$ & 132 & $123^{*}$ & $111^{*}$ & $108^{*}$ & $102 *$ & $100 *$ & 3,23 \\
\hline
\end{tabular}

(1)Efeito linear $(\mathrm{p}<0,05)$ - equação: $\mathrm{Y}=0,55-0,005 \mathrm{X} ; \mathrm{R}^{2}=0,79$. ${ }^{(2)}$ Efeito linear $(\mathrm{p}<0,05)$ - equação: $\mathrm{Y}=78,84+0,91 \mathrm{X} ; \mathrm{R}^{2}=0,82$. ${ }^{(3)}$ Efeito linear $(p<0,05)$ - equação: $Y=125,49-1,21 X ; R^{2}=0,80$. *Diferente em relação ao controle, pelo teste de Dunnett a 5\% de probabilidade. 


\section{Conclusões}

1. O farelo de castanha de caju (FCC), utilizado na alimentação de frangos de corte, não compromete o desempenho nas diferentes fases de criação.

2. A inclusão do FCC na ração para frangos de corte, a partir de $10 \%$, melhora o ganho de peso e a conversão alimentar.

\section{Referências}

BAIÃO, N.C.; LARA, L.J.C. Oil and fat in broiler nutrition. Revista Brasileira de Ciência Avícola, v.7, p.129-141, 2005.

EMBRAPA. Centro Nacional de Pesquisa de Suínos e Aves (Concórdia, SC). Tabela de composição química e valores energéticos de alimentos para suínos e aves. 3.ed. Concórdia: Embrapa-CNPSA, 1991. 97p. (Embrapa-CNPSA. Documentos, 19).

FURLAN, A.C.; MANTOVANI, C.; MURAKAMI, A.E.; MOREIRA, I.; SCAPINELLO, C.; MARTINS, E.N. Utilização do farelo de girassol na alimentação de frangos de corte. Revista Brasileira de Zootecnia, v.30, p.158-164, 2001.

GRANGEIRO, M.G.A.; FUENTES, M.F.F.; FREITAS, E.R.; ESPÍNDOLA, G.B.; SOUZA, F.M. Inclusão da levedura de canade-açúcar (Saccharomyces cerevisiae) em dietas para frangos de corte. Revista Brasileira de Zootecnia, v.30, p.766-773, 2001.

JENSEN, L.S. Subproductos de animales en las formulaciones. Industria Avícola, v.38, p.28-31, 1991.

LEESON, S.; SUMMERS, D.J. Nutrition of the chicken. $4^{\text {th }}$ ed. Ontario: University Books, 2001. 413p.

MARTINS, R.T.; CASCABULHO, A.R.; BAIÃO, N.C.; AFONSO, R.J.G.F. Efeito do tipo de óleo de soja na composição em ácidos graxos da carcaça de frangos de corte. Arquivo Brasileiro de Medicina Veterinária e Zootecnia, v.55, p.92-98, 2003.
NATIONAL RESEARCH COUNCIL (Washington, Estados Unidos). Nutrient requirements of poultry. $9^{\text {th }} \mathrm{ed}$. Washington: National Academy Press, 1994. 155p.

OJEWOLA, G.S.; OKOYE, F.C.; AGBAKURU, I. Replacement value of cashew-nut meal for soybean meal in finishing broiler chickens. International Journal of Poultry Science, v.3, p.513516, 2004.

OLIVEIRA NETO, A.R.; OLIVEIRA, R.F.M.; DONZELE, J.L.; ROSTAGNO, H.S.; FERREIRA, R.A.; CARMO, H.M. Níveis de energia metabolizável para frangos de corte no período de 22 a 42 dias de idade mantidos em ambiente termoneutro. Revista Brasileira de Zootecnia, v.29, p.1132-1140, 2000.

ONIFADE, A.A.; TEWE, O.O.; FANIMO, A.O.; OKUNOLA, O.O.; AFOLABI, A.B. Replacement value of cashew nut meal for groundnut-cake in pullet diets: effect on pre-laying performance and serum biochemical indices. Indian Journal of Animal Science, v.68, p.273-275, 1998.

ONIFADE, A.A.; TEWE, O.O.; OKUNOLA, O.O.; FANIMO, A.O. Performance of laying pullets fed on cereal-free diets based on maize offal, cassava peel and reject cashew nut meal. British Poultry Science, v.40, p.84-87, 1999.

PIMENTEL, C.R.M. Castanha de caju: produção e consumo internacional. Fortaleza: Embrapa-CNPCa, 1992. 18p.

PRODUÇÃO AGRÍCOLA MUNICIPAL: culturas temporárias e permanentes 2003. Rio de Janeiro: IBGE, v.30, 2003. 93p.

SAKOMURA, N.K.; LONGO, F.A.; RABELLO, C.B.; WATANABE, K.; PELÍCIA, K.; FREITAS, E.R. Efeito do nível de energia metabolizável da dieta no desempenho e metabolismo energético de frangos de corte. Revista Brasileira de Zootecnia, v.33, p.1758-1767, 2004.

SAKOMURA, N.K.; SILVA, R.; LUCEUSENTZ, A.C. Avaliação da soja integral tostada ou extrusada sobre o desempenho de frangos de corte. Revista Brasileira de Zootecnia, v.27, p.584-594, 1998. SAS INSTITUTE (Cary, Estados Unidos). SAS user's guide: statistics. $12^{\text {th }}$ ed. Cary, 1996. 965p.

WALDROUP, P.W. Dietary nutrient allowances for chickens and turkeys. Feedstuffs, v.63, p.70-77, 1991. 